\title{
Are Financial Markets Efficient?
}

\section{Arturo Rubalcava*}

Faculty of Business Administration, University of Regina, Canada

Whether financial markets (mainly U.S. equity markets) are efficient [1-6] has been a topic of discussion in the popular financial press and also in academic journals for some decades. Events in earlier years (e.g., US stock market crash of 1987, dot-com bubble of 2000) were followed by the financial market meltdown in 2008 , the examples of successful investors who have beaten the market repeatedly, the occurrence of socalled market anomalies, and the emerging of financial behaviourists, increased interest in market efficiency. One issue in this debate is the meaning of efficient markets, a concept that appears to be subject to misunderstanding or is not sufficiently clarified, and that still remain a sensitive research issue among academics. The concept of market efficiency has been extensively documented and this piece does not pretend to make a full review of the theoretical, empirical work and controversies surrounding it. The main objective is to shed light about one of its main implications, that is, that in an efficient equity market an investor - individual, financial or non-financial institution- cannot systematically obtain positive excess profits by trading securities.

Are market crashes or bubbles evidence against market efficiency? Can investors benefit from these events? To begin, a brief review of the theoretical concept of market efficiency or the efficient market hypothesis (EMH) is worth examining. Eugene Fama, a prominent finance scholar, published a seminal paper in 1970 that developed the concept of market efficiency which took three forms [7]. First, a market is efficient in the strong form if the price of securities (e.g., equities) fully reflect all available information (public and private). An implication of this is that insiders (e.g., company officers) cannot take advantage of their privileged (private) information (e.g., an important discovery of diamond's mine) by buying stock and selling it at a higher price upon the announcement of the good news, thereby profiting from their information access [8]. This trading upon insider information is contrary to the norms of the financial industry and is illegal, and may result in financial penalties as well as incarceration as shown in recent highly publicized cases. While these may act to deter insiders from acting illegally, it is difficult to assess how much illegal activity by insiders actually occurs.

Second, markets can be nearly efficient (the semi-strong form). This means that the announcement of a firm-specific event or the occurrence of other type of economic, social or natural events (e.g., unexpected changes in interest rates, social unrest, or an earthquake) that may affect the profitability of a firm will have an immediate impact on the firm's stock price. Since the stock price would reflect instantaneously the value of the news, investors cannot profit from it. Fama [9] and Brown [5] cite various studies that support this form of market efficiency. For example, the collapse of the financial system in 2008 was triggered by a battery of negative events emanating from Wall Street such as the announcement of the insolvency of Lehman Brother's investment bank. The value of this negative news was reflected immediately in its stock price and the stock price of others financial institutions linked to Lehman's. Since the announcement of this event was unexpected, it is unlikely that investors were able to profit from it.

The third form of market efficiency (the weak-form), asserts that the price of a security today reflects the value of firm-specific or economic events that have occurred in the past and that may had material effect in the company profits. The implication of this is that investors cannot use trading rules based on the behavior of firm's past prices to obtain risk adjusted excess-returns. This implies that the expected price of a stock at the end of the day should be equal to yesterday's price plus its risk adjusted expected daily return plus the value of new information (positive or negative) which is random. There is some ex-post evidence that this form of market efficiency may not hold $[9,10]$. That is, these studies indicate that return may be predictable based on history of past returns such that investors can use trading strategies based on the pattern of past prices. However, Fama [9] argues that these predictable profits -if they actually occur- would be short lived, for example, as other mimic those practices. Also as there is limited agreement on what actually generates predictable profits [10], it becomes less likely that investors can systematically profit by following trading rules based on past pattern of prices.

Do successful investment careers contradict the efficient market hypothesis? These success stories include Peter Lynch, who as a manager of the Magellan Fund repeatedly outperformed most of the time the S\&P 500 Index benchmark from 1977 to 1990 [11], Bill Miller, a mutual fund manager of the Legg Mason Value Trust who holds the impressive record of beating the S\&P for 15 consecutive years [12], and Warren Buffet 'considered the most successful investor of the $20^{\text {th }}$ century' [13]. The success of these skilled investors has been based mostly by assessing correctly the fundamental or fair value of firm's stock price relative to its market price which is determined by supply and demand. If the fundamental value is above the market price a profit may be obtained by taking long positions on the undervalued stock and selling it when the market price reaches its fair value. Similarly, if the fundamental value is below the market price a profit may be obtained by selling the stock short (i.e., borrowing the stock from a broker and selling it immediately at the higher market price; when it reaches its fair (low) value, the stock is bought and returned it to the broker, profiting from the difference net of transaction costs). These examples of high performance demonstrate that some techniques, and approaches (such as long range perspectives in the context of fundamental analysis) using the same information available to others, can results in stock selections that result in superior performance over time. However, it is also clear that many investors mimic the investment decisions of notables, thereby resulting in lower possibilities of generating consistent excess profits for some of the parties involved. Thus, the competitive process of detecting mispriced securities actually makes the market more efficient, that is, market prices reflecting their fundamentals. Generally then, it appears that variation in techniques and acumen are not completely accounted for the efficient market hypothesis.

*Corresponding author: Arturo Rubalcava, Faculty of Business Administration, University of Regina, Canada, Tel: 306-337-2388; E-mail: Arturo.Rubalcava@uregina.ca

Received June 27, 2013; Accepted July 01, 2013; Published July 04, 2013

Citation: Rubalcava A (2013) Are Financial Markets Efficient? J Bus \& Fin Aff 2:e136. doi:10.4172/2167-0234.1000e136

Copyright: ( 2013 Rubalcava A. This is an open-access article distributed under the terms of the Creative Commons Attribution License, which permits unrestricted use, distribution, and reproduction in any medium, provided the original author and source are credited. 
Finally, isn't the return record of Lynch, Miller, and Buffet evidence against market efficiency? If consistent performance is defined as always outperforming the market, the answer is no. For instance, Lynch didn't beat the S\&P 500 during 2 of the 13 years in which he managed the Magellan Fund. Bill Millers' fund dramatically underperformed the S\&P 500 benchmark index in 2006 [14]. Also, Warren Buffet's wealth decreased by $\$ 6$-billion during 2010 while other prominent investors such as George Soros increased [15]. These cases are evidence, consistent with the implication of the efficient market hypothesis, that is, investors cannot consistently outperform their benchmark.

Similarly, aren't documented market anomalies associated with recurrent excess returns such as day of the week effect (lower returns on Mondays compared to other days), January effect (higher returns on January relative to other months), or size effect (investing in small companies generate excess returns compared to large firms) [9] contrary to market efficiency? Studies report that once the returns are adjusted by risk and transaction costs, investors are unable to generate significant profits [16,17]. Another criticism of the efficient market hypothesis is made by financial behaviourists who assert that investors are not as rational as the EMF posits $[18,19]$, that is, investors are prone to behaviours that can be detrimental to their wealth. For instance, buying or selling securities when everybody else is doing it (i.e., herding) or selling (buying) when the markets is down (up), without examining the stock's fundamentals. In fact, these behaviours may occur from time to time which could move prices beyond their fundamental value. The issue is: can investors take advantage of this 'irrational' behaviour? It is difficult to determine since irrational behaviour is hard to identify ex-ante no less to profit from it $[16,20]$. For example, herding may be rational if circumstances change, but may be irrational if people are simply following the leader.

An alternative and promising approach to the efficient market and behavioral finance developed by Andrew Lo [21] called Adaptive Market Hypothesis (AMH), may be the venue to reconcile these views and solve those issues. Briefly, the AMH hypothesis is based as a starting point in the $\mathrm{EMH}$, a frictionless system where no capital market imperfections would occur, e.g., transaction costs, taxes, and behavioral biases or 'irrationality'. However, environmental changes, in which investors might not be prepared, make them prone to 'irrational' behavior from the point of view of behaviorists but sub-optimal from the view of the AMH. Lo [21] argue that this behaviour in an evolutionary context is normal since investors by trying to adapt to the changing and highly competitive new environment can make mistakes or act irrationally. He adds that in the presence of such real-world imperfections, the laws of natural selection or, more appropriately, "survival of the richest", determine the evolution of markets and institutions.' According to Lo [21], the profile of the successful investors fits into this natural selection context.
In summary, the empirical evidence shows that inability of investors to consistently obtain risk adjusted excess profits net of transaction costs indicates that markets may be considered fairly efficient. This does not rule out that the market value of securities may misalign to their fundamental value (creating profit opportunities for shrewd investors), or that market anomalies do not exist or financial bubbles would not occur. New approaches beyond those supporting efficient markets or behavioral finance, such as the AMH may be needed to provide more insights on the issues that still remain as puzzles in the investment environment.

\section{References}

1. http://www.economist.com/node/14030296

2. http://www.economist.com/node/14165405

3. http://online.wsj.com/article/SB1000142405274870357360457449126190516 5886.html

4. http://www.princeton.edu/ceps/workingpapers/200malkiel.pdf

5. Brown SJ (2011) The efficient market hypothesis: The demise of the demon of chance? Accounting and Finance 51: 79-95.

6. http://papers.ssrn.com/sol3/papers.cfm?abstract_id=991509

7. Fama E (1970) Efficient capital markets: a review of theory and empirical work Journal of Finance 25: 383-417.

8. http://en.wikipedia.org/wiki/Category:People_convicted_of_insider_trading

9. Fama E (1991) Efficient capital markets: II. Journal of Finance 46: 1575-1617.

10. Jegadeesh, N, Titman S (2001) Profitability of momentum strategies: An evaluation of alternative explanations. Journal of Finance 56: 699-720.

11. http://www.investopedia.com/university/greatest/peterlynch.asp

12. http://www.investopedia.com/university/greatest/billmiller.asp

13. http://en.wikipedia.org/wiki/Warren_Buffett

14. http://www.theglobeandmail.com/globe-investor/investment-ideas/why-istopped-trying-to-beat-the-market/article4183688/

15. http://dailycaller.com/2011/09/21/soros-joins-forbes-top-10-u-s-billionaires-list/

16. Malkiel B (2003) The efficient markets hypothesis and its critics. Journal of Economic Perspectives 17: 59-82.

17. http://papers.ssrn.com/sol3/papers.cfm?abstract_id=991509

18. Thaler R (1993) Advances in Behavioral Finance. New York: Russell Sage Foundation, New York, USA.

19. http://papers.ssrn.com/sol3/papers.cfm?abstract_id $=349660$

20. Malkiel BG (2012) Bubbles in Asset Prices PART IV. The Oxford Handbook of CAPITALISM, Oxford University Press.

21. http://papers.ssrn.com/sol3/papers.cfm?abstract_id=728864 